\title{
Multi Floral Honey Has a Protective Effect against Mammary Cancer Induced by 7,12-Dimethylbenz(a)anthracene in Sprague Dawley Rats
}

\author{
Hamed R. Takruri ${ }^{1}$, Maha S. Shomaf ${ }^{2} \&$ Saida F. Shnaigat ${ }^{1}$ \\ ${ }^{1}$ Department of Nutrition and Food Technology, Faculty of Agriculture, The University of Jordan, Amman, \\ Jordan \\ ${ }^{2}$ Department of Pathology and Microbiology and Forensic Medicine, The University of Jordan, Amman, Jordan \\ Correspondence: Hamed R. Takruri, Department of Nutrition and Food Technology, Faculty of Agriculture, The \\ University of Jordan, Amman 11942, Jordan. E-mail: htakruri@ju.edu.jo
}

Received: November 8, 2016

Accepted: December 14, 2016

Online Published: January 15, 2017

doi:10.5539/jas.v9n2p196

URL: http://dx.doi.org/10.5539/jas.v9n2p196

\begin{abstract}
This research was conducted to study the protective effect of bee honey on the 7,12-dimethylbenz( $\alpha$ )anthracene (DMBA)- induced breast cancer in rat model. The study consisted of three groups: honey group, positive control group (PC), and negative control group (NC) to which the carcinogen was not administered. All rats were fed the diet recommended by the American Institute of Nutrition for growing rats (AIN-93G), with addition of honey $(50 \mathrm{~g} / \mathrm{kg}$ diet) to the honey group. All Rats were fed their diets ad libitum on 12 hours dark/light cycle. At the age of 50 days all rats in the honey and PC groups were gavaged once by the carcinogen DMBA with a dose of 80 $\mathrm{mg} / \mathrm{kg}$ body Wt. After three weeks of carcinogen administration, rats were palpated weekly to detect any tumor growth. After 18 weeks, all rats were sacrificed. The palpable structures and the mammary glands along with associated lymph nodes were removed and fixed in saline formalin and prepared for histopathological examination. The results revealed that the honey group diet significantly $(p<0.05)$ reduced the incidence rate of mammary cancer, palpable tumor multiplicity, tumor size and weight compared to the PC group. In conclusion, multi floral honey has a protective effect against DMBA- induced mammary cancer in the initiation, promotion, and progression stages of DMBA-induced mammary carcinogenesis. However, further research is needed to reveal the mechanisms that might have contributed to the preventive effect of honey against mammary cancer.
\end{abstract}

Keywords: multifloral honey, mammary cancer, 7,12-dimethylbenz(a)anthracene, DMBA, Sprague Dawley rats

\section{Introduction}

Breast cancer can be defined as a neoplastic change in the epithelial cells of mammary tissue, particularly in the epithelium of mammary ducts (Hieger, 1961). It is considered an important cause of women suffering and mortality worldwide (Coughlin \& Cypel, 2013). Incidence and death rates of breast cancer increase with age. About $95 \%$ of new cases occur in women 40 years of age and older. In the United States, incidence rates of breast cancer continue to rise after menopause and are highest in the older age categories (Wingo et al., 2008). Also, Forouzanfar et al. (2011) reported that more than two-thirds of breast cancer cases are diagnosed in women aged 50 years and older, and that the majority of these cases belong to developed countries.

The Ministry of Health $(\mathrm{MOH})$ in Jordan published in their 15th annual (2010) report on cancer incidence and epidemiology that the total number of new cancer cases was 6820 , of them 4921 were Jordanians (72.2\%). Of the cancer cases, $19.6 \%$ had breast cancer, making it number one among cancers in Jordanian females (MOH, 2010). The etiology of breast cancer is largely unknown (Debruin \& Josephy, 2002). About $90-95 \%$ of all cancer cases can be attributed to environmental and lifestyle factors, whereas the remaining $5-10 \%$ belong to genetic defects (Anand et al., 2008). Because of this high contribution of environmental factors, the health care providers always search for food components that may act against cancer. One of the successful strategies for cancer prevention is through increasing the consumption of functional foods which can be found naturally in foods or added to them as functional ingredients (Zeng et al., 2013).

Honey is known for centuries for its medicinal and health promoting effects. It contains various kinds of phytochemicals with high phenolic and flavonoid contents which contribute to its high antioxidant activity (Pyrzynska \& Biesaga, 2009). Among the functional components of honey are: chrysin and other flavonoids 
which exert beneficial effects against tumor cell proliferation (Tonks, Cooper, Price, Molan, \& Jones, 2001). Due to its strong antioxidant property, honey may have the potential to prevent the development of cancer, as free radicals and oxidative stress play a significant role in the induction of cancers (Valko et al., 2007). Additionally, honey was reported to be a natural immune booster, natural anti-inflammatory agent, natural antimicrobial agent, natural promoter for healing chronic ulcers and wounds, and natural cancer vaccine (Othman, 2012). The carcinogen 7,12-dimethylbenz $(\alpha)$ anthracene (DMBA) is one of the two most commonly used substances to study mammary cancer in rodents (Guzman et al., 1999). Therefore, the aim of this experiment was to study the effect of honey on the incidence of breast cancer in rat model in which cancer was induced by (DMBA) through examining their effects on the multiplicity of tumors, tumor size, and tumor latency.

\section{Materials and Methods}

\subsection{Animals}

Thirty nine weanling female Sprague Dawley rats, three weeks of age (40-50 g), were used in the study. They were purchased from the Animal House of Jordan University of Science and Technology and were transferred to the animal unit/Department of Nutrition and Food Technology/Faculty of Agriculture/The University of Jordan. They were placed at a controlled temperature of $23 \pm 2{ }^{\circ} \mathrm{C}$, humidity of $49 \pm 5 \%$, and 12-hour light-dark cycle. The rats were divided into three experimental groups 13 rats in each: honey group, positive control group (PC), and negative control group (NC).

\subsection{Preparation of the Experimental Diets}

Animals were fed isocaloric and isonitrogenous diet which was prepared according to the Guidelines of the American Institute of Nutrition 1993 for growing animals (AIN-93 G), recommended by Reeves (1997) (Table 1) with some modifications as follows:

1) Soybean oil was replaced by an oil mixture that consists of canola oil and sunflower oil in a ratio of 0.7:1.0 (Al-Sayyed \& Takruri, 2016), since soybean has been documented to be protective against breast cancer.

2) Multifloral honey was added to the honey group diet in a concentration of $50 \mathrm{~g} / \mathrm{kg}$ diet. For this group we added only $50 \mathrm{~g}$ of sucrose instead of $100 \mathrm{~g}$ to have an isocaloric diet.

Table 1. Components of test diets for the different experimental groups

\begin{tabular}{lll}
\hline \multirow{2}{*}{ Component (g or $\mathrm{mg} / \mathrm{kg}$ diet) } & \multicolumn{2}{c}{ Experimental groups } \\
\cline { 2 - 3 } & AIN Diet & Honey \\
\hline Corn starch & 529.5 & 529.5 \\
Casein & 200 & 200 \\
Sucrose & 100 & 100 \\
Oil mixture & 70 & 70 \\
Fiber & 50 & 50 \\
Mineral mix & 35 & 35 \\
Vitamin mix & 10 & 10 \\
L-Cystine & 3.0 & 3.0 \\
Choline bitartarate & 2.5 & 2.5 \\
TBHQ (mg) & 14 & 14 \\
Honey & - & 50 \\
\hline
\end{tabular}

Note. TBHQ: Tertiary Butylatedhydroquinone.

Source: Reeves (1997).

\subsection{Preparation and Administration of Carcinogen}

DMBA carcinogen (Santa Cruz Biotechnology/USA, purity $\geq 98 \%$ ) was prepared by dissolving it in acetone and suspending it in sesame oil as described by Daniel and Richard (1964) and Lin et al. (2008). Then acetone was evaporated gently under liquid nitrogen.

At 50 days of age rats in the PC and honey groups (but not the NC group) were gavaged with a single dose of the sesame oil containing DMBA in a concentration of $80 \mathrm{mg} / \mathrm{kg}$ BW. After three weeks of carcinogen 
administration, the rats were palpated once weekly by a veterinarian to record the appearance of any abnormal masses or tumors (Bradly, Kledzig, \& Meites, 1976).

At the termination of the experiment after 18 weeks of carcinogen application, all rats were killed by chloroform anesthesia.The palpable structures, mammary tissues (cervical, thoracic, abdominal, and inguinal) and associated lymph nodes were removed with the help of a veterinarian, and then stored by submerging in $10 \%$ saline formalin. The dimensions of the masses were determined via digital caliper (TRESNA, USA) and weighed before storing them in formalin until histopathological examination.

Tissue slides were prepared according to the procedure of Russo and Russo (2000) and were examined to confirm the presence of tumor, and identify its type under light microscope (OLYMPUS, USA) (40, 100X power) by a histopathologist.

\subsection{Statistical Analysis}

The statistical analysis was performed by using SPSS program. The data of tumor latency, and tumor size were analyzed by one way analysis of variance (ANOVA) test. Different treatment groups were compared to detect the statistical significance using Fischer test for mean separation. Differences were considered significant at $\mathrm{p}<$ 0.05.The data of tumor incidence, as well as malignant and benign tumor multiplicities were analyzed by Chi square test $\left(\mathrm{X}^{2}\right)$ for equal proportions. Differences between treatments were considered significant at $\mathrm{p}<0.05$.

\section{Results}

\subsection{Incidence of Malignant Tumors and Adenosis}

Results of histopathological examination showed that the malignant mammary tumors that were developed in the rats are invasive mammary carcinomas (IMC); these are of the same histological type of human tumors.

Table 2 presents the incidence of invasive mammary carcinoma (IMC) and adenosis in the study groups. It shows that the PC group had the highest incidence of tumors (4 rats out of 13, (30.8\%)) among the experimental groups with significant differences $(p<0.05)$ from the negative control and honey groups. There was no incidence of IMC neither in the NC group nor in the honey group. Figure 1 demonstrates the presence of IMC in the PC rats.

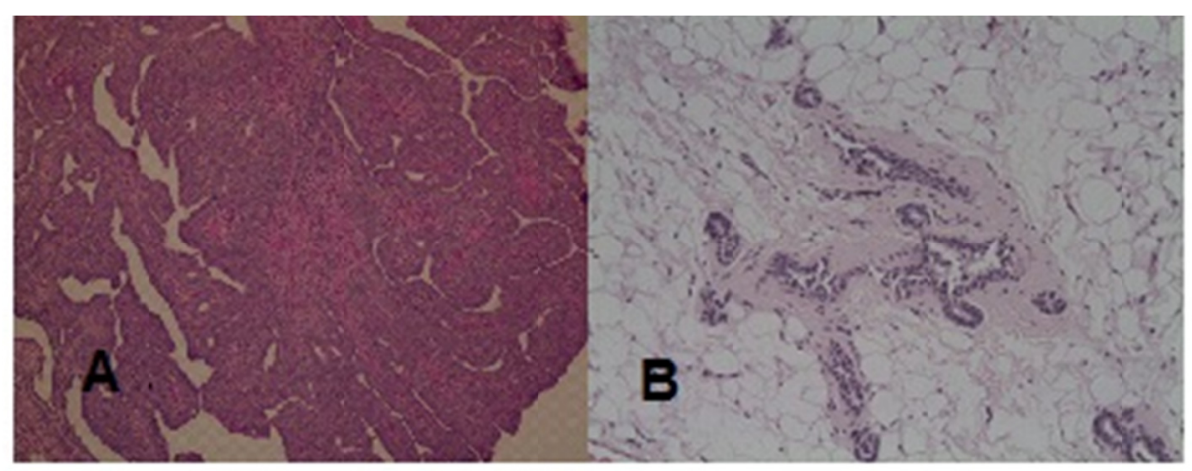

Figure 1. Histology of mammary tissue with (A) IMC in the PC rat group compared to (B) Normal mammary tissue (H\&E stain, 100X)

The histopathological examination of rat tissues also revealed that adenosis had occurred (Table 2). The PC group had the highest incidence of adenosis cases ( 7 out of 13 rats making up 53.9\%). The incidence of adenosis in this group was significantly higher $(\mathrm{p}<0.05)$ than that of the NC group which had no adenosis incidence $(0 \%)$. The honey group, on the other hand, had 4 (30.8\%) cases of adenosis, which is significantly lower than that of the $\mathrm{PC}$ group. 
Table 2. Incidence of IMC, and adenosis among the experimental groups ${ }^{1}$

\begin{tabular}{lll}
\hline Group (n) & $\mathrm{IMC}^{3}$ & Adenosis $^{4}$ \\
\hline NC group (13) & $0(0 \%)^{\mathrm{a}}$ & $0(0 \%)^{\mathrm{a}}$ \\
PC group (13) & $4(30.8 \%)^{\mathrm{b}}$ & $7(53.9 \%)^{\mathrm{c}}$ \\
Honey group (13) & $0(0 \%)^{\mathrm{a}}$ & $4(30.8 \%)^{\mathrm{b}}$ \\
\hline
\end{tabular}

Note. ${ }^{1}$ Data expressed as number of cases and percentages, values with different litters within a column differ significantly at $(p<0.05)$ using Fischer test; ${ }^{2} n$ : number of rats used within each experimental group; ${ }^{3}$ Incidence of invasive mammary carcinoma; ${ }^{4}$ Adenosis: pro-carcinogenic or initiation stage.

\subsection{Multiplicity of IMC, Site and Latency}

Table 3 shows the multiplicity of IMC (expressed as total number of IMC/group) among the experimental groups. Only the PC group rats had high multiplicity of IMC (4 rats) whereas the NC and honey groups did not have any IMC as they did not have any tumors.

Table 3 also expresses the tumor latency (days) for the PC group (54.33 \pm 10.81 days) in opposite to the NC and honey groups which did not have any malignant growths after 18 weeks of DMBA administration.

Regarding the site of palpable tumors, in this experiment IMC was developed in the inguinal and thoracic mammary glands. Three tumors (IMC) were developed in the inguinal mammary glands, whereas 1 tumor was developed in the thoracic mammary gland in the PC group rats.

Table 3. Multiplicity of IMC, site and latency

\begin{tabular}{llll}
\hline${\text { Group }(\mathrm{n})^{1}}^{1}$ & ${\text { Multiplicity of } \mathrm{IMC}^{2}}$ & Site & Latency $^{3}$ \\
\hline NC group (13) & 0 & 0 & No Tumors Detected \\
PC group (13) & 4 & 2 right inguinal & $53.33 \pm 10.81$ \\
& & 1 left inguinal & \\
& 1 right thoracic & No Tumors Detected \\
Honey group (13) & 0 & 0 & .
\end{tabular}

Note. ${ }^{1} \mathrm{n}$ : number of rats used within each experimental group; ${ }^{2}$ multiplicity of invasive mammary carcinoma; ${ }^{3}$ Number of days after carcinogen administration till the onset of the palpable tumor, expressed as mean day \pm SEM.

\subsection{Average of the Largest Diameter and Average Weight of Palpable Tumors}

Table 4 shows that the largest average diameter of palpable tumors in the PC group was $(20.81 \pm 4.18 \mathrm{~mm})$ and that the average tumor weight (expressed as $\mathrm{g} /$ tumor/ tumor bearing rat) in this control group was $(3.23 \pm 1.58 \mathrm{~g})$.

Table 4. Average largest diameter and average weight of the palpable tumors

\begin{tabular}{llll}
\hline Group (n) & $\mathrm{IMC}^{2}$ & $\begin{array}{l}\text { Largest diameter of the palpable tumors } \\
(\mathrm{mm} / \text { tumor/tumor bearing rat })^{3}\end{array}$ & $\begin{array}{l}\text { Average tumor weight } \\
(\mathrm{g} / \text { tumor/tumor bearing rat) }\end{array}$ \\
\hline NC group (13) & 0 & No tumor & No tumor \\
PC group (13) & 4 & $20.81 \pm 4.18$ & $3.23 \pm 1.58$ \\
Honey group (13) & 0 & No tumor & No tumor
\end{tabular}

Note. ${ }^{1}$ n: number of rats used within each experimental group; ${ }^{2}$ multiplicity of invasive mammary carcinoma;

${ }^{3}$ Values of size of tumor and its weight are expressed as mean \pm SEM.

\subsection{Incidence and Multiplicity of Benign Palpable Structures (BPS) among the Experimental Groups}

Table 5 shows that 2 incidences of BPS occurred only in honey group (15.4\%), with 3 multiplicities whereas the $\mathrm{NC}$ and PC groups did not develop any BPS. There was no significant difference $(\mathrm{p}>0.05)$ between the experimental groups. 
Table 5. Incidence and multiplicity of benign palpable structures (BPS) among the experimental groups ${ }^{1}$

\begin{tabular}{lll}
\hline Group $(\mathrm{n})^{2}$ & Incidence of BPS & Multiplicity of BPS \\
\hline NC group (13) & $0(0 \%)$ & 0 \\
PC group (13) & $0(0 \%)$ & 0 \\
Honey group (13) & $2(15.4 \%)$ & 3 \\
\hline
\end{tabular}

Note. BPS: benign palpable structure, data are expressed as total number of BPS/group and\% from the number of animals in the group; ${ }^{2} \mathrm{n}$ : number of rats used within each experimental group.

\section{Discussion}

\subsection{Incidence of Malignant Tumors and Adenosis among the Experimental Groups}

The incidence of IMC, which represents the malignant tumors, occurred only in the PC group rats $(4,30.8 \%)$. The results of this study also showed that the honey group had no incidence of IMC which suggests that honey has protective effect against mammary cancer in rats. Several studies reported that honey has a strong antioxidant capacity (Yao, Datta, \& Tomas-Barberan, 2003; Lurlina, Saiz, Fritz, \& Manrique, 2009). These antioxidant effects of honey have the potential to prevent the development of cancer (Valko et al., 2007). Honey is rich in phytochemicals such as phenolic acids and polyphenols. The different polyphenols in honey were reported to have antiproliferative effects against several types of cancers (Jaganathan \& Mandal, 2009).

These results are in agreement with those obtained in a Malaysian study, in which it was found that Tualang honey positively modulated the progression of DMBA-induced breast cancer in rats. Tumors were much less in number, volume, and weight in honey-treated rats compared to rats in the control group (AbdKadir, Sulaiman, Yahya, \& Othman, 2013). Phenolic compounds, such as quercetin, were reported to induce apoptotic effects through estrogen receptors alpha and beta dependent mechanisms (Bulzomi et al., 2012). It is noteworthy that the amount of quercetin in honey is relatively high, making up $43 \mu \mathrm{g} / 100 \mathrm{~g}$ honey (Kurtagic, Redzig, Memic, \& Sulejmanovic, 2013).

Fauzi, Norazmi, and Yaacop (2011) mentioned that honey has cytotoxic effects in the human breast cancer cell lines MCF-7, and these effects were not shown in normal breast cell lines MCF-10 A. This suggests that the cytotoxic effects of honey are selective and specific to the breast cancer cell line only unlike most of anticancer drugs. Therefore, flavonoids and phenolic compounds in honey seem to be responsible for the cytotoxic effects on cancer cells (Erejuwa, Sulaiman, \& Wahab, 2014).

Antimetastatic, antiproliferative, and anticancer effects of honey against breast cancer in rodents were also reported in other studies. Honey flavonoids particularly chrysin was shown to have antimetastatic effects against human breast cancer cells (Yang et al., 2013). Also it was reported that the anticarcinogenic activity of honey is due to its antiestrogenic effects and its potential in inducing mitochondrial membrane depolarization and apoptosis in breast cancer cells (Erejuwa et al., 2014). It was mentioned that the higher the phenolic content in honey, the greater its antitumor effects are (Jaganathan, Mondhe, Wani, Pal, \& Mandal, 2010).

The histopathological examination in this experiment revealed an incidence of adenosis in the mammary tissues of the rats. The American Cancer Society ACS (2015) describes adenosis as an enlargement of breast lobules which contain more glands than usual. Other names of adenosis include: aggregate adenosis, tumoral adenosis, or adenosis tumor. However, adenosis is not a cancer, but can be developed later into a cancer. It is an early stage of the carcinogenesis process and keeping the tumor in the initiation stage.

The enlarged lobules may be distorted by a scar- like fibrous tissue in a condition known as sclerosing adenosis (SA) which is a special type of adenosis. In humans, having an SA increases the woman's risk for having breast cancer by two fold (ACS, 2015). SA is considered as an important entity for clinicians, because it mimics breast carcinoma clinically and on mammography. Some studies reported that SA represents a proliferative process which can lead to carcinomatous changes (Azzopardi, 1979).

The results of this study showed that the percentage of adenosis cases was in the PC group (58.3\%), followed by the honey group (30.8). It has been reported that spontaneous tumors of different types and different body sites could happen in female Sprague Dawley rats with age, even with no induced carcinogenesis (Morii \& Fujii, 1973). However the NC group rats in our study did not develop any tumor or even adenosis probably because of the short period of the experiment (18 weeks; 126 days) in comparison with 701 days in Morii \& Fujii study. 


\subsection{Multiplicity of IMC and Tumor Latency}

The progression stage of carcinogenesis is characterized by further metabolism of the carcinogen which leads to additional lesions, malignancy, and growth of the tumors (Tsuda et al., 2004).Tumor growth can occur as a result of the proliferation of cancer cells (Ju et al., 2001). The results of this study showed that there was tumor multiplicity in 4 rats of the PC group, whereas the other experimental groups (negative control and honey groups) did not develop any cancer growth.

Tumor latency represents the period between DMBA administration and the appearance of palpable tumors. Latency period in DMBA- induced mammary cancer is a function of the promotion stage of carcinogenesis (Hieger, 1961). The promotion stage represents the time period starting after carcinogen administration. This period is characterized by the growth of mammary tumors (Welcsh, 1992). The delay in the appearance of palpable tumors indicates lower growth rate of tumor (Kodell \& Chen, 2001). Also, this period is characterized by a loss of cell differentiation and disordered cell growth (Tsuda et al., 2004). In this experiment tumor latency for the PC group was $54.33 \pm 10.81$ days, which is similar to the results obtained by Al-Sayyed, Takruri, and Shomaf (2014) who reported a latency period of 50 days in Sprague Dawley rats in which cancer was induced by DMBA.

\subsection{Incidence and Multiplicity of Benign Palpable Structures among the Experimental Groups}

The incidence of benign palpable structures (BPS) was reported by several researchers. They reported that a single intragastric dose of DMBA could induce benign mammary tumors in SD female rats (Noble \& Cutts, 1959; Dias et al., 1999). Dias et al. (1999) documented an incidence rate of $34 \%$ for the benign mammary tumors after a single dose of $65 \mathrm{mg}$ of DMBA administered into female Wistar rats. The variation in the incidence rates and multiplicities of BPS among different studies might be related to experimental conditions. In the present study, Sprague Dawley rats were used, the DMBA dose was $80 \mathrm{mg}$ and the experimental period was 18 weeks only, whereas the experimental period in the Dias etal study was 24 weeks.

Mann, Boorman, Lollini, Mc Martin, and Goodman, (1996) reported that there are three types of benign neoplasms in rat mammary glands including: fibroadenoma, fibroma, and adenoma. The most common benign neoplasms that occur in rat mammary gland is fibroadenoma. This type of neoplasm consists of both connective tissue and mammary epithelial cells. The proportion of these two cell types varies considerably from one tumor to another. Some tumors consist mainly of epithelial cells, whereas others are composed almost entirely of connective tissue.

Fibroma is another type of benign neoplasms in which the tumors are composed entirely of collagenous connective tissue without any epithelial component and which arise in the subcutaneous regions. The third type of benign neoplasms in rat mammary gland is adenoma. Tumors which represent this type are composed almost entirely of glandular epithelial structures with a scant connective tissue stroma. The epithelium is usually uniform with a cuboidal to columnar shape (Mann et al., 1996).

Abd El-Aziz et al. (2005) mentioned that mammary carcinogenesis can lead to hormonal disturbances, and accordingly, DMBA may induce hormonal disturbances. These disturbances might have led into the development of BPS, but not to adinocarcinoma. Other researchers reported that the incidence of BPS might be attributed to endocrine influences, particularly the estrogen hormone (Nobel \& Cutts, 1959; Santner, Pauley, Tait, Kasenta, \& Santen, 1997). In the present study, the incidence of BPS occurred only in the honey group which might indicate a protective effect of honey against carcinosis.

\section{Conclusions}

Based on the results of this study, it can be concluded that multifloral honey has protective effects against DMBA- induced mammary cancer in the initiation, promotion, and progression stages of DMBA-induced mammary carcinogenesis, as indicated by incidence rate, tumor latency, multiplicity and size.This effect was probably due to the strong antioxidants activity of honey.

\section{Acknowledgements}

This research was supported by Abdul Hameed Shoman Foundation Fund for Scientific Research, The Deanship of Academic Research at the University of Jordan, and the Scientific Research Support Fund/Ministry of higher education and scientific research, Jordan.

\section{References}

Abd El-Aziz, M., Hassan, H., Mohamed, M., Meki, A., Abdel-Ghaffar, S., \& Hussein, M. (2005). The biochemical and morphological alterations following administration of melatonin, retinoic acid and Nigella 
sativa in mammary carcinoma: An animal model. International Journal of Experimental Pathology, 86, 383-396. https://doi.org/10.1111/j.0959-9673.2005.00448.x

AbdKadir, E., Sulaiman, S., Yahya, N., \& Othman, N. (2013). Inhibitory Effects of Tualang Honey on Experimental Breast Cancer in Rats: A Preliminary Study. Asian Pacific Journal of Cancer Prevention, 14(4), 2249-2254. https://doi.org/10.7314/APJCP.2013.14.4.2249

Al-Sayyed, H., \& Takruri, H. (2016). Modification of American Institute of Nutrition Rat Diet in Mammary Cancer Research. Journal of Agricultural Science, 8(5). https://doi.org/10.5539/jas.v8n5p173

Al-Sayyed, H. F., Takruri, H. R., \& Shomaf, M. S. (2014). The Effect of Date Palm Fruit (Phoenix dactylifera L.) on 7,12-Dimethylbenz $(\alpha)$ anthracene (DMBA)-Induced Mammary Cancer in Rts. Research Opinions in Animal \& Veterinary Sciences, 4(1), 11-18.

Anand, P., Kunnumakkara, A., Sundaram, C., Harikumar, K., Tharakan, S., Lai, O., ... Aggarwal, B. (2008). Cancer is a preventable disease that requires major lifestyle changes. Pharmaceutical Research, 25(9), 2097-2116. https://doi.org/10.1007/s11095-008-9661-9

Azzopardi, J. (1979). Problems in breast pathology (pp. 168-174). Philadelphia: WB Saunders.

Bradley, C., Kledzik, G., \& Meites, J. (1976). Prolactin and Estrogen Dependency of Rat Mammary Cancers at Early and Late Stages of Development. Cancer Research, 36, 319-24.

Bulzomi, P., Galluzzo, P., Bolli, A., Leone, S., Acconcia, F., \& Marino, M. (2012). The Pro-apoptotic Effect of Quercetin in Cancer Cell Lines Requires ER $\beta$-Dependent Signals. Journal of Cellular Physiology, 227(5), 1891-1898. https://doi.org/10.1002/jcp.22917

Coughlin, S., \& Cypel, Y. (2013). Epidemiology of Breast Cancer in Women. https://doi.org/10.1007/978-14614-5647-6-2

Daniel, P., \& Richard, M. (1964). Three Types of Mammary Tumour Induced in Rats by Feeding with DMBA. British Journal of Cancer, 18(3), 513-520. https://doi.org/10.1038/bjc.1964.58

Debruin, L., \& Josephy, P. (2002). Perspectives on the Chemical Etiology of Breast Cancer. Environmental Health Perspectives, 110, 119-128. https://doi.org/10.1289/ehp.02110s1119

Dias, M., Cabrita, S., Sousa, E., França, B., Patrício, J., \& Oliveira, C. (1999). Benign and malignant mammary tumors induced by DMBA in female Wistar rats. European Journal of Gynecological Oncology, 4, 285-288.

Erejuwa, O., Sulaiman, S., \& Wahab, M. (2014). Effects of honey and its mechanisms of action on the development and progression of cancer. Journal of Molecules, 19(2), 2497-522. https://doi.org/10.3390/ molecules 19022497

Fauzi, A., Norazmi, M., \& Yaacob, N. (2012). Tualang honey induces apoptosis and disrupts the mitochondrial membrane potential of human breast and cervical cancer cell lines. Journal of Food and Chemistry and Toxicology, 49, 871-878. https://doi.org/10.1016/j.fct.2010.12.010

Forouzanfar, M., Foreman, K., Delossantos, A., Lozano, R., Lopez, A., Murray, C., \& Naghavi, M. (2011). Breast and cervical cancer in 187 countries between 1980 and 2010: A systematic analysis. Lancet, 378, 1461-1484. https://doi.org/10.1016/S0140-6736(11)61351-2

Guzman, R., Yang, J., Rajkumar, L., Thordarson, G., Chen, X., \& Nandi, S. (1999). Hormonal prevention of breast cancer: Mimicking the protective effect of pregnancy. Proceedings of the National Academy of Science of the United States of America, 96(5), 2520-2525. https://doi.org/10.1073/pnas.96.5.2520

Hieger, I. (1961). Carcinogenesis (1 st ed.). London and New York: Academic Press.

Jaganathan, S., \& Mandal, M. (2009). Antiproliferative Effects of Honey and of Its Polyphenols: A Review. Journal of Biomedicine and Biotechnology, 13. https://doi.org/10.1155/2009/830616

Jaganathan, S., Mondhe, D., Wani, Z., Pal, H., \& Mandal, M. (2010). Effect of Honey and Eugenol on Ehrlich Ascites and Solid Carcinoma. Journal of Biomedicine and Biotechnology, 5. https://oi.org/10.1155/ 2010/989163

Ju, Y., Allred, C., Allred, K., Karko, K., Doerge, D., \& Helferich, W. (2001). Physiological concentrations of dietary genistein dose-dependently stimulate growth of estrogen-dependent human breast cancer (MCF-7) tumors implanted in athymic nude mice. The Journal of Nutrition, 131, 2957-2962. 
Kodell, R., \& Chen, J. (2001). Inferring Effects on Tumor Frequencies and Times to Observation in the Analysis of Tumor Multiplicity Data. Biometrical Journal, 43, 447-460. https://doi.org/10.1002/1521-4036(200108) 43:4<447::AID-BIMJ447>3.0.CO;2-J

Kurtagic, H., Redzic, S., Memic, M., \& Sulejmanovic, J. (2013). Identification and Quantification of Quercetin, Naringenin and Hesperetin by RP LC-DAD in Honey Samples from B\&H. Bulletin of the Chemists and Technologists of Bosnia and Herzegovina, 40, 25-30.

Lin, Y., Collier, A., Liu, W., Berry, M., \& Panee, J. (2008). The inhibitory effect of bamboo extract on the development of 7,12 dimethylbenz[a]anthracene (DMBA)-induced breast cancer. Phytotherapy Research, 22, 1440-1445. https://doi.org/10.1002/ptr.2439

Lurlina, M., Saiz, A., Fritz, R., \& Manrique, G. (2009). Major flavonoids of Argentinean honeys. Optimisation of the extraction method and analysis of their content in relationship to the geographical source of honeys. Journal of Food Chemistry, 115(3), 1141-1149. https://doi.org/10.1016/j.foodchem.2009.01.003

Mann, P., Boorman, G., Lollini, L., Mc Martin, D., \& Goodman, D. (1996). Proliferative lesions of the mammary gland in rats. Guides for Toxicologic Pathology, 2, 1-11.

Ministry of Health/Non Communicable Disease Directorate. (2010). Jordan Cancer Registry: Cancer Incidence in Jordan 2010 (15th report). The Hashemite of Jordan.

Morii, S., \& Fujii, T. (1973). Spontaneous tumors in Sprague-Dawley JCL rats. Experimental Animal Journal (Tokyo), 22, 127.

Nobel, R., \& Cutts, T. (1959). Mammary Tumors of The Rats: A Review. Cancer Research, 19, 1125-1139.

Othman, N. (2012). Honey and Cancer: Sustainable Inverse Relationship Particularly for Developing Nations-A Review. https://doi.org/10.1155/2012/410406

Pyrzynska, K., \& Biesaga, M. (2009). Analysis of phenolic acids and flavonoids in honey. Trends in Analytical Chemistry, 28(7), 893-902. https://doi.org/10.1016/j.trac.2009.03.015

Reeves, P. (1997). Components of the AIN_93 diets as improvements in the AIN_76 A diet. The Journal of Nutrition, 127, 838-842.

Russo, J., \& Russo, I. (2000). Atlas and Histologic Classification of Tumors of the Rat Mammary Gland. Journal of Mammary Gland Biology and Neoplasia, 5(2), 187-200. https://doi.org/10.1023/A:1026443305758

Santner, S., Pauley, R., Tait, L., Kaseta, J., \& Santen, R. (1997). Aromatase Activity and Expression in Breast Cancer and Benign Breast Tissue Stromal Cells. Journal of Clinical Endocrinology and Metabolism, 82, 200-208. https://doi.org/10.1210/jcem.82.1.3672

Tonks, A., Cooper, R., Price, A., Molan, P., \& Jones, K. (2001). Stimulation of TNF- $\alpha$ Release in Monocytes by Honey. Cytokine, 14(4), 240-242. https://doi.org/10.1006/cyto.2001.0868

Tsuda, H., Ohshima, Y., Nomoto, H., Fujita, K., Matsuda, E., Iigo, M., ... Moore, M. (2004). Review: Cancer Prevention by Natural Compounds. Drug Metabolism and Pharmacokinetics, 19(4), 245-263. https://doi.org/10.2133/dmpk.19.245

Valko, M., Leibfritz, D., Moncol, J., Cronin, M., Mazur, M. \& Telser, J. (2007). Review: Free radicals and antioxidants in normal physiological functions and human disease. The International Journal of Biochemistry \& Cell Biology, 39(1), 44-84. https://doi.org/10.1016/j.biocel.2006.07.001

Welsch, C. (1992). Relationship between Dietary Fat and Experimental Mammary Tumorigenesis: A Review and Critique. Cancer Research, 52(7), 2040S-2048S.

Wingo, P., King, J., Swan, J., Coughlin, S., Kaur, J., Erb-Alvarez, J., ... Arambula, S. (2008). Breast cancer incidence among American Indian and Alaska native women: US, 1999-2004. Cancer, 113(5), 1191-1202. https://doi.org/10.1002/cncr.23725

Yao, L., Datta, N., \& Tomas-Barberan, F. (2003). Flavonoids,mphenolic acids and abscisic acid in Australian and New Zealand Leptospermum honeys. Journal of Food Chemistry, 81, 159-168. https://doi.org/10.1016/ S0308-8146(02)00388-6

Yang, B., Huang, J., Xiang, T., Yin, X., Luo, X., Huang, J., ... Ren, G. (2013). Chrysin inhibits metastatic potential of human triple-negative breast cancer cells by modulating matrix metalloproteinase-10, epithelial to mesenchymal transition, and PI3K/Akt signaling pathway. Journal of Applied Toxicology, 34(1), 105-112. https://doi.org/10.1002/jat.2941 
Zeng, Y., Yang, J., Pu, X., Du, J., Yang, T., Yang, S., \& Zhu, W. (2013). Strategies of functional food for cancer prevention in human beings. Asian Pacific Journal of Cancer Prevention, 14, 1585-1592. https://doi.org/ 10.7314/APJCP.2013.14.3.1585

\section{Copyrights}

Copyright for this article is retained by the author(s), with first publication rights granted to the journal.

This is an open-access article distributed under the terms and conditions of the Creative Commons Attribution license (http://creativecommons.org/licenses/by/4.0/). 